\title{
Lidar observations of the diurnal variations in the depth of urban mixing layer: A case study on the air quality deterioration in Taipei, Taiwan
}

\author{
Charles C.-K. Chou ${ }^{a, *}$, C.-T. Lee ${ }^{\text {b }}$, W.-N. Chen ${ }^{\text {a }}$, S.-Y. Chang ${ }^{a}$, \\ T.-K. Chen ${ }^{\text {a }}$, C.-Y. Lin ${ }^{\text {a }}$, J.-P. Chen ${ }^{c}$ \\ ${ }^{a}$ Research Center for Environmental Changes, Academia Sinica, Taipei 115, Taiwan, ROC \\ ${ }^{\mathrm{b}}$ Graduate Institute of Environmental Engineering, National Central University, ChungLi 320, Taiwan, ROC \\ ${ }^{\mathrm{c}}$ Department of Atmospheric Sciences, National Taiwan University, Taipei 106, Taiwan, ROC
}

Received 28 April 2006; received in revised form 1 November 2006; accepted 23 November 2006

Available online 31 January 2007

\begin{abstract}
An aerosol light detection and ranging (LIDAR) system was used to measure the depth of the atmospheric mixing layer over Taipei, Taiwan in the spring of 2005. This paper presents the variations of the mixing height and the mixing ratios of air pollutants during an episode of air quality deterioration (March 7-10, 2005), when Taipei was under an anti-cyclonic outflow of a traveling highpressure system. It was found that, during those days, the urban mixing height reached its daily maximum of $1.0-1.5 \mathrm{~km}$ around noon and declined to $0.3-0.5 \mathrm{~km}$ around 18:00 (LST). In terms of hourly averages, the mixing height increased with the ambient temperature linearly by a slope of $166 \mathrm{~m} /{ }^{\circ} \mathrm{C}$ in daytime. The consistency between the changes in the mixing height and in the ambient temperature implied that the mixing layer dynamics were dominated by solar thermal forcing. As the cap of the mixing layer descended substantially in the afternoon, reduced dispersion in the shallow mixing layer caused the concentrations of primary air pollutants to increase sharply. Consequently, the pollutant concentration exhibited an anti-correlation with the mixing height. While attentions are usually focused on the pollution problems occurring in a morning inversion layer, the results of this study indicate that the air pollution and its health impacts could be even more severe as the mixing layer is getting shallow in the afternoon.
\end{abstract}

(C) 2006 Elsevier B.V. All rights reserved.

Keywords: Urban mixing layer; LIDAR; Urban air quality; Tropospheric aerosols

\section{Introduction}

The mixing layer is the lowest part of the atmosphere where the constituents of air are mixed due to convection and mechanical turbulence over the ground (Seibert et al.,

\footnotetext{
* Corresponding author. Tel.: +88622653 9885; fax: +88622783 3584 .

E-mail address: ckchou@rcec.sinica.edu.tw (C.C.-K. Chou).
}

2000). Because the emission of air pollutants due to human activities are mostly from ground-level sources, mixing layer is usually the most polluted part of the atmosphere, particularly over urban and industrial areas. Considering that the air in the mixing layer is what people actually breathe, its composition is therefore of great public concern, and the air quality is generally defined by the concentrations of air pollutants in the mixing layer.

Given that the dispersion of air pollutants is often confined within the mixing layer, the depth of the 
mixing layer, which is usually referred to as the "mixing height", is one of the most critical parameters in air quality studies. For decades, there has been a consensus that the deterioration of air quality is usually caused by the formation of a shallow mixing layer (e.g., Turner, 1969). However, to date, mixing height is not measured routinely at most air quality stations. Meteorological radiosonde stations may be the only regular data sources for determining this atmospheric structure. Yet the radiosondes are usually launched at 00 and 12 UTC only. Thus, in our time zone (GMT+0800), the sonding measurements are made in the morning and early evening, respectively, each day. The lack of daytime (particularly mid-day) data prevents us from deciphering the diurnal variations of air quality. In recent years, continuous measurements of the mixing height have been successfully carried out using the aerosol LIDAR (LIght Detecting And Ranging) technique (e.g., Flamant et al., 1997; Menut et al., 1999; Cohn and Angevine, 2000; Chen et al., 2001; Matthias and Bosenberg, 2002; Kunz et al., 2002; Angevine et al., 2003; Mok and Rudowicz, 2004). With the advantages of a high temporal resolution, LIDAR can provide valuable data for understanding the mixing layer dynamics. Furthermore, as the aerosol itself is one of the major air pollutants in an urban atmosphere, the LIDAR signals are essential for understanding the vertical distribution of air pollutants.

Analyses of the seasonal variations of the air pollutants in Taipei, Taiwan show that their concentrations usually reached the maxima in spring. In addition to possible long-range transport from Asian pollution outbreaks (e.g., Dibb et al., 2003; Chou et al., 2005), local factors such as a shallow mixing layer may also contribute to the high pollution in springtime. In this study, a LIDAR system was used to measure the mixing height over Taipei Basin, Taiwan during a spring pollution episode. The drastic variations of the mixing height and its implications for the high levels of air pollutants are discussed. Meteorological conditions and mechanism for the development of a shallow mixing layer in the afternoon are identified. The results indicate the critical role of the mixing layer dynamics in the formation of a pollution episode.

\section{Methods}

\subsection{Data sources}

Data used in this study includes the mass concentrations of PM10 and PM2.5 (particulate matter with an aerodynamic diameter of less than 10 and $2.5 \mu \mathrm{m}$, respectively) and light scattering coefficient (at $550 \mathrm{~nm}$ ) measured at the Taipei (SinJhuang) Supersite. The mixing ratios of gaseous air pollutants $\left(\mathrm{CO}, \mathrm{O}_{3}, \mathrm{SO}_{2}\right.$, $\mathrm{NO}_{x}$, Total Hydrocarbons, Non-Methane Hydrocarbons) measured at the SinJhuang air quality monitoring station of Taiwan EPA, as well as meteorological parameters (barometric pressure, ambient temperature, and surface wind field) measured at the BanChio observatory of the Central Weather Bureau of Taiwan were also analyzed. In addition, the vertical profiles of aerosol in the troposphere, and the depth of the mixing layer over Taipei were obtained from a ground-based LIDAR system installed on campus of the National Taiwan University. All measurements were assimilated with a time resolution of $1 \mathrm{~h}$. These measurement sites are within $15 \mathrm{~km}$ of each other, as shown in the map given in Fig. 1.

\subsection{Instrumentation}

At the Taipei Supersite, the concentrations of PM10 and PM2.5 are measured simultaneously using two TEOM (Tapered Element Oscillating Microbalance, Model 1400a, Rupprecht and Patashnick Co., Inc., U.S.A). The light scattering coefficients for 450, 550, and $700 \mathrm{~nm}$ are measured by a three-wavelength nephelometer (Model 3563, TSI Inc., USA); however, only those for $550 \mathrm{~nm}$ will be presented in this paper because the variations in the scattering coefficients of the other two wavelengths were consistent with that of $550 \mathrm{~nm}$ in this episode. The sulfate, nitrate, and carbonaceous constituents in the aerosols are also measured at the supersite. The results of the aerosol composition will be presented and discussed in a separate paper.

At the SinJhuang air quality station, which is part of the Taiwan Air Quality Monitoring Network (TAQMN) established by the Taiwan EPA in 1993, the mixing ratios of $\mathrm{SO}_{2}, \mathrm{NO}_{x}$, and $\mathrm{O}_{3}$ are measured using the instruments manufactured by the Ecotech Inc. (Model 9850, 9841, and 9810, respectively), CO is measured by a NDIR-based monitor (Model APMA-360, HORIBA Ltd., Japan), and those of hydrocarbons are measured using a flame ionization detector (Model APHA-360, HORIBA Ltd., Japan).

The LIDAR used in this study is a dual-wavelength system employing the second and third harmonics of Nd-YAG laser at $532 \mathrm{~nm}$ and $355 \mathrm{~nm}$ with a pulse repetition rate of $20 \mathrm{~Hz}$. The transmitted laser beams are directed vertically into the atmosphere. A Newtonian telescope with a diameter of $40 \mathrm{~cm}$ is used as the receiver for the backscattered light. Two narrow band interference filters (wavelength center at $355 \mathrm{~nm}$ and 


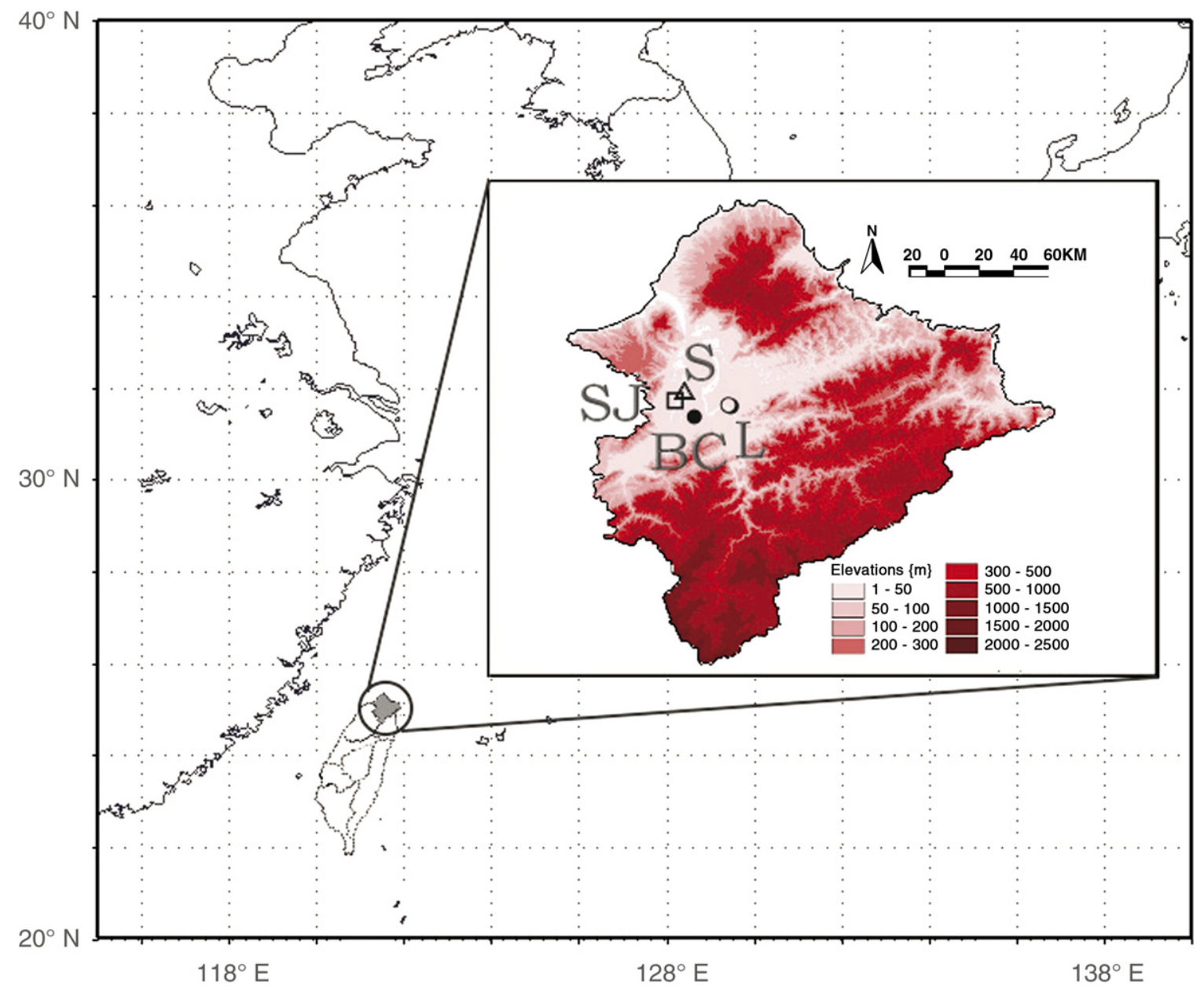

Fig. 1. Geographical locations of the observatories in Taipei Basin. ( $\square$ SJ: SinJhuang air quality station; $\triangle \mathrm{S}$ : supersite; $@$ L: lidar observatory; $\bigcirc B C$ : BanChiao meteorological station).

$532 \mathrm{~nm}$ ) with full width at half maximum (FWHM) of $0.5 \mathrm{~nm}$ are used to reject the background light. An additional narrow band filter of $387 \mathrm{~nm}$ with an FWHM of $3 \mathrm{~nm}$ is employed to measure the Raman signals of nitrogen at nighttime. The LIDAR was operated $24 \mathrm{~h}$ each day to probe the atmosphere, and the signals returned from 0.3 to $8 \mathrm{~km}$ were analyzed in this work. The raw data resolution of our LIDAR measurement is $7.5 \mathrm{~m}$.

\subsection{LIDAR data processing and mixing height determination}

The signal detected by LIDAR is usually described in terms of the range-squared-corrected signal (RSCS), which is defined as

$\operatorname{RSCS}=\left[P(\lambda, z)-P_{\mathrm{B}}(\lambda, z)\right] \times z^{2}$ where $P(\lambda, z)$ and $P_{\mathrm{B}}(\lambda, z)$ denote the power of the backscattered light and the background signal from an altitude of $z$, respectively. The backscattering coefficient of aerosols can be obtained from the inversion of the LIDAR signal following the LIDAR equation:

$P(\lambda, z)=\frac{P_{0}(\lambda) A(\lambda)}{z^{2}}\left(\beta_{m}(\lambda, z)+\beta_{a}(\lambda, z)\right) e^{-2 \int_{0}^{x}\left[\sigma_{m}(\lambda, z)+\sigma_{a}(\lambda, z)\right] d z}$

where $P_{0}(\lambda)$ is the transmitted power; $A(\lambda)$ is the system calibration factor; $\sigma_{m, a}(\lambda, z)$ and $\beta_{m, a}(\lambda, z)$ denote the extinction and backscattering coefficients of the molecular (subscript $m$ ) and aerosol (subscript $a$ ) constituents in the atmosphere. For nighttime measurement, the calculation of $\beta_{a}$ is based on the Raman inversion algorithm (Ansmann et al., 1992), whereas the daytime $\beta_{a}$ is calculated using a fixed lidar ratio obtained from 

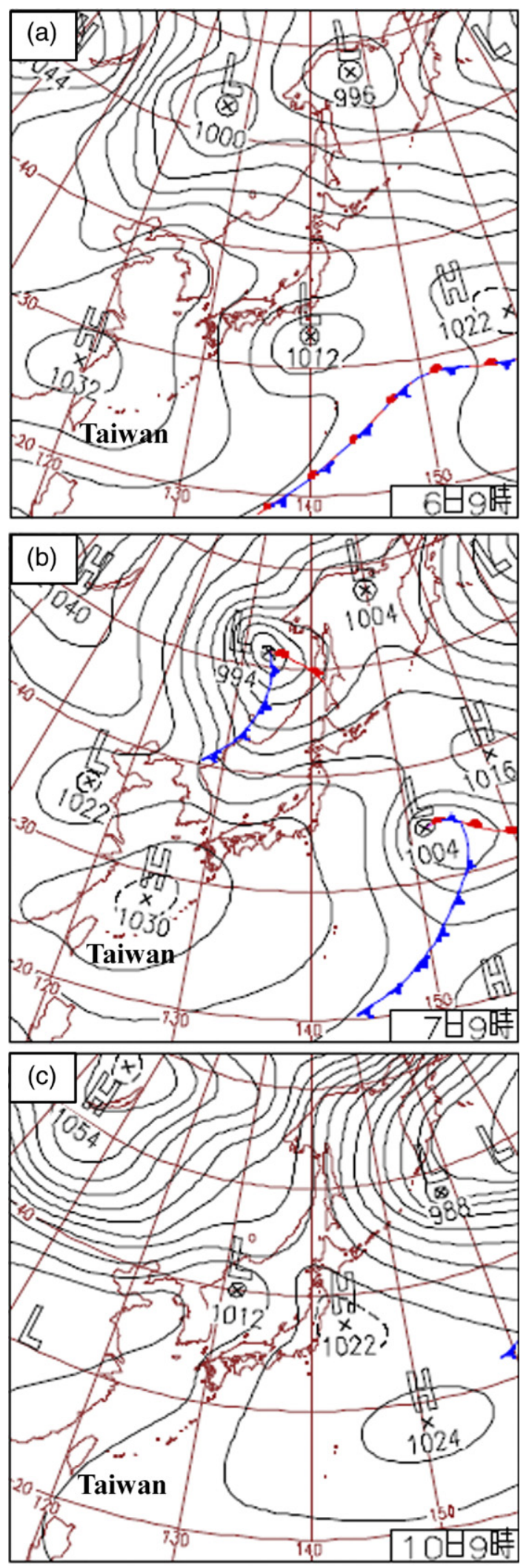

the Raman measurements of the previous night (Klett, 1981). Lidar ratio depends strongly on the aerosol composition as well as the size distribution. Nevertheless, in this study, the measured lidar ratios $(355 \mathrm{~nm})$ for aerosols within boundary layer were mostly ranged from $30 \mathrm{sr}$ to $50 \mathrm{sr}$, and the standard deviation of the lidar ratio for one night usually less than 10 sr. Thus, in case the nighttime Raman measurement is also not available, a fixed lidar ratio of $40 \mathrm{sr}$ would be applied.

Given that the aerosol concentration in the mixing layer is significantly higher than in the free troposphere, the cap of the mixing layer is characterized by a steep gradient of the aerosol backscattering signal. Flamant et al. (1997) proposed that the altitude of the top of the mixing layer could be obtained from the profile of the derivative of the LIDAR signal (i.e. RSCS). In a preliminary study, we have validated the mixing height measurement of our LIDAR system by comparing with that determined using radiosondes (Chen et al., 2006). Accordingly, in this study, the mixing height is defined at the altitude with the minimum of the first derivative of RSCS (i.e. $\mathrm{dPz}^{2} / \mathrm{dz}$ ). With this definition, the mixing height cannot be determined in the case of a stable atmosphere where a very shallow inversion layer could exist. Given the $300 \mathrm{~m}$ altitude gate of our LIDAR, we'll only report that the mixing height was less than $0.3 \mathrm{~km}$ for those cases.

\section{Results and discussion}

\subsection{Meteorological conditions}

Fig. 2 shows the evolution of the synoptic weather systems over East Asia, and indicates that a strong traveling high-pressure system moved along the $30^{\circ} \mathrm{N}$ latitude line, from the Southeast China into the West Pacific Ocean during the period of March 6-10, 2005. Fig. 3(a) illustrates that the barometric pressure (BP) at Taipei reached a high level of $1030 \mathrm{hPa}$ in the early morning of March 6, indicating that Taipei was rather close to the high center. As the high-pressure system was moving away, leaving Taipei under its anti-cyclonic subsidence, the BP gradually decreased and during that time the ambient temperature (AT) varied with typical diurnal cycles until the next cold front arrived in the early morning of March 11 . The variations of the surface

Fig. 2. Surface weather maps for $0000 Z$ of (a) March 6; (b) March 7; (c) March 10, 2005. A traveling high-pressure system was moving along $30^{\circ}$ $\mathrm{N}$ from the East China into the West Pacific Ocean. Taipei was on the leeward side of its anti-cyclonic outflow during March 7-10. (Source: Japan Meteorological Agency). 

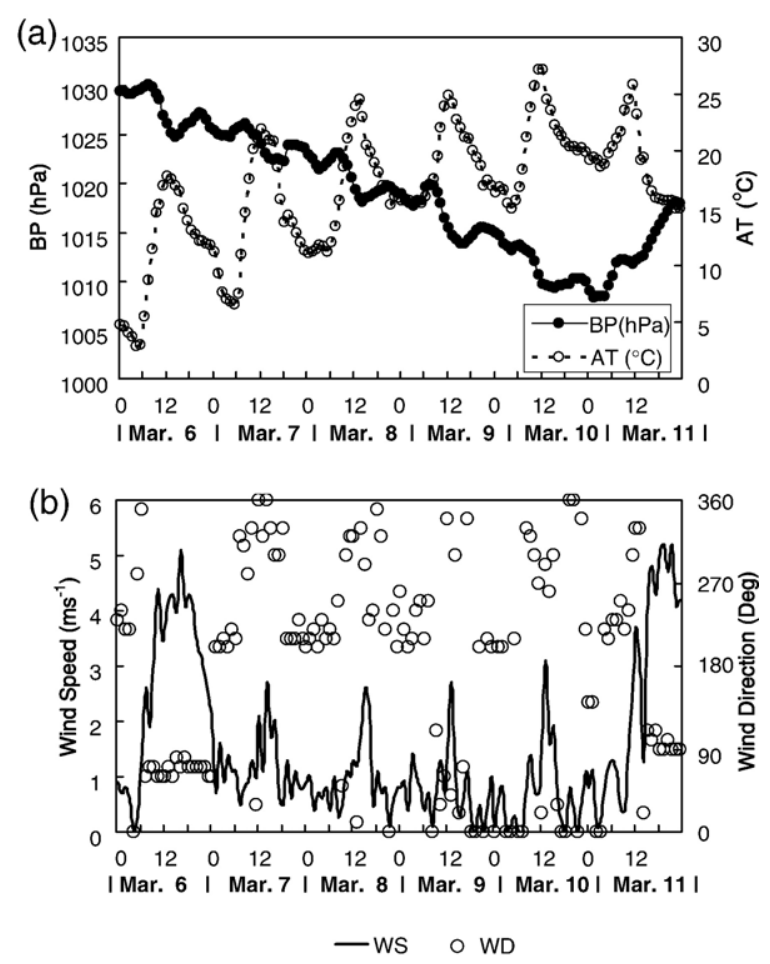

Fig. 3. Hourly variations of (a) barometric pressure, ambient temperature, and (b) surface winds during the episode of this study.

winds are shown in Fig. 3(b): When the high-pressure system was passing through Taipei, there were first strong easterlies caused by the steep pressure gradient at the edge of the high-pressure air mass. The following days (March 7-10) were characterized by weak synoptic winds. Under this setting, moderate sea breezes $(2-3 \mathrm{~m} / \mathrm{s})$ developed each afternoon as a result of the land-heating effects. It is worth noting that the wind speed decreased drastically while the ambient temperature declined, and that the sea-breeze peaks in Fig. 3(b) are exactly coincidental with those of the ambient temperature shown in Fig. 3(a). The synchronization between the ambient temperature and the wind speed implies that thermo-forcing was dominant in the boundary layer dynamics in those days, when Taipei was on the leeward side of the high mountains $(\sim 2000 \mathrm{~m})$ located on the southeastern rim of the basin.

\subsection{Variations in mixing height}

The height of the mixing layer was obtained from the profile of the backscattering signals measured by the LIDAR system. To demonstrate the typical diurnal variation of the mixing layer, Fig. 4(a)-(b) shows the time-altitude evolution of the Lidar signal (RSCS) and its first derivative, respectively, for March 7, 2005. The boundaries between the mixing layer and the free troposphere were distinctly characterized by the sharp gradient of the aerosol signals. In the morning, most of the aerosols were confined within the surface-based inversion layer. The aerosol layer at $0.8-1 \mathrm{~km}$ is most likely remnants of the convectively elevated mixing layer from the previous day. The inversion started to break up at about 09:00 (Local Time) and the mixing layer was thickening. The LIDAR signals clearly show the evolution of the atmospheric boundary layer, transforming from a stratified to a well-mixed structure in the morning toward the noon. The mixing height reached a maximum of $1460 \mathrm{~m}$ AGL at noon. Fig. 4(b) and (c) illustrates the evolution in the vertical profile of the Lidar signal $(532 \mathrm{~nm})$. Note that, as shown by the profiles for 12:00 and 14:00 LST, the aerosol backscattering ratio was consistent in the lowest part of the atmosphere, indicating the existence of a well-mixed boundary layer. In this case the boundary layer agrees with the mixing layer essentially. However, from the derivative of the LIDAR signals shown in Fig. 4(b), we found that a "sandwich" structure was developed in the lower troposphere in the late afternoon. While the strong inversion between the free troposphere and the boundary layer was still there, the vertical mixing had declined substantially and cannot support a mixing layer as high as that at the noontime. As a result, the boundary layer was divided into two parts: the lower part was the mixing layer where the convection was still predominant; the upper part was known as the residual layer that contained the aerosols lifted up in the noontime boundary layer. Fig. 5 shows the temperature profiles retrieved from the radiosonde measurements made at 08:00 and 20:00 (LST), respectively, on March 7. The formation of the surface-based inversion layers should have inhibited the convective mixing, and the mixing height cannot be defined in this context. One can also see the inversion at $1.0-1.2 \mathrm{~km}$ in the evening profile, which is corresponding to the boundary between the residual layer and the free troposphere observed by the LIDAR. The evolution of the boundary layer observed in our study agrees generally with those documented in the literature (e.g., Stull, 1988; Cohn and Angevine, 2000). This consistency warrants a further analysis of the boundary layer dynamics based on the LIDAR measurements.

It is worth noting that the mixing height decreased drastically in the afternoon, implying that the development of the nocturnal boundary layer could have started several hours prior to sunset. Consequently, a substantial 
(a) Range Corrected Singal

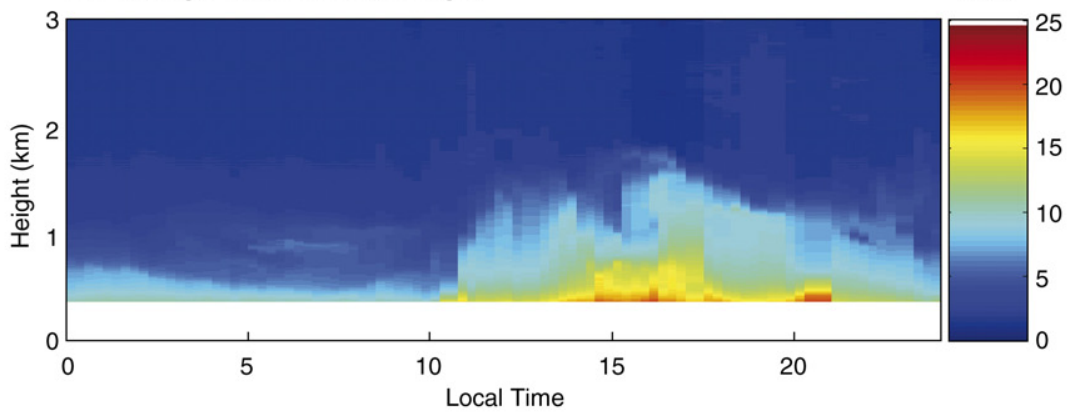

(b) $d\left(P x z .{ }^{2}\right)$

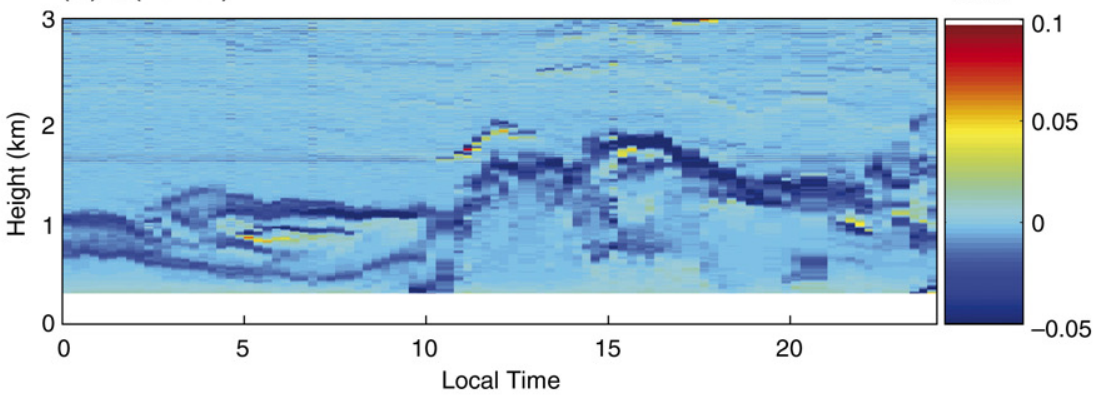

(c) 2005/3/7 Backscattering Ratio (532 nm)

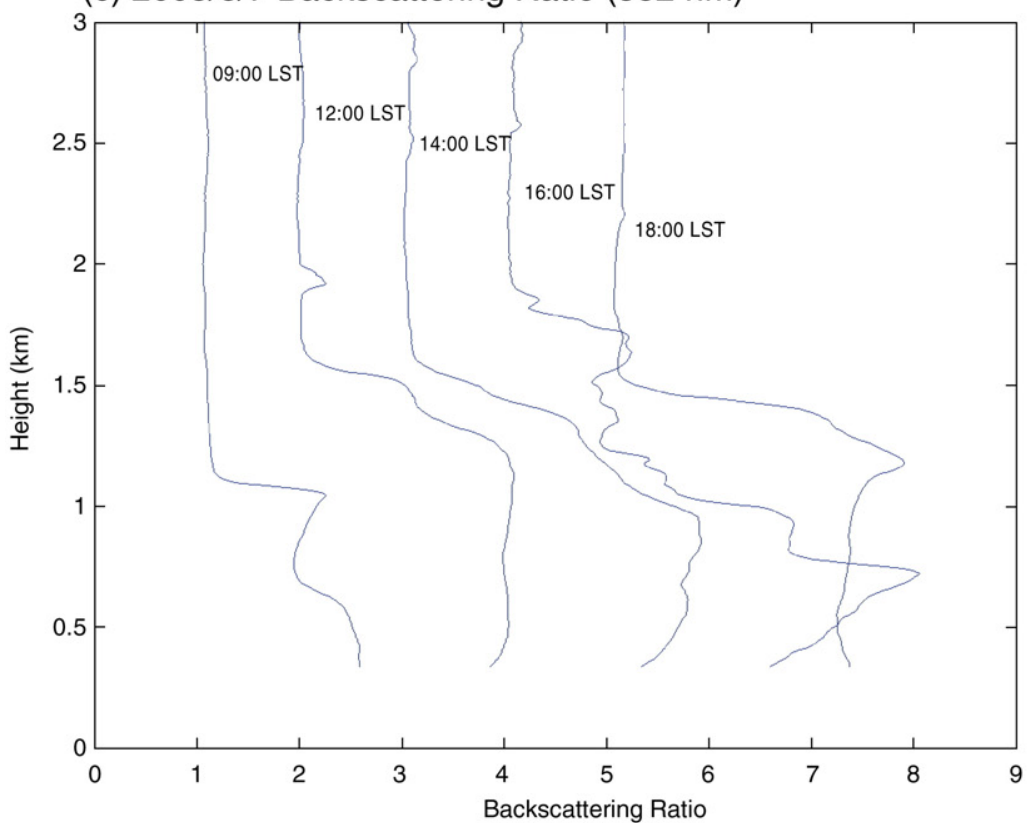

Fig. 4. Evolution of Lidar measurements on March 7, 2005. (a) range-squared-corrected signal; (b) first derivative of the LIDAR signal; (c) vertical profiles of the backscattering coefficient measured at 9:00, 12:00, 14:00, 16:00, and 18:00 (LST). The offset of each profile was shifted for presentation. Figures (a) and (b) present 15-min averages of the LIDAR measurements and have a resolution of $7.5 \mathrm{~m}$ in altitude.

amount of air pollutants could have been stored in the residual layer and negatively influencing the air quality in the downwind area as the mixing layer developed in the next morning. Such a drastic decrease of the mixing height in the afternoon is similar to that observed by
Strawbridge and Snyder (2004) in British Columbia, Canada, and the simulation for a case in Barcelona, Spain (Pino et al., 2004). Grimsdell and Angevine (2002) identified two types of afternoon transition of the boundary layer: inversion layer separation (ILS) and 
(a) Temperature

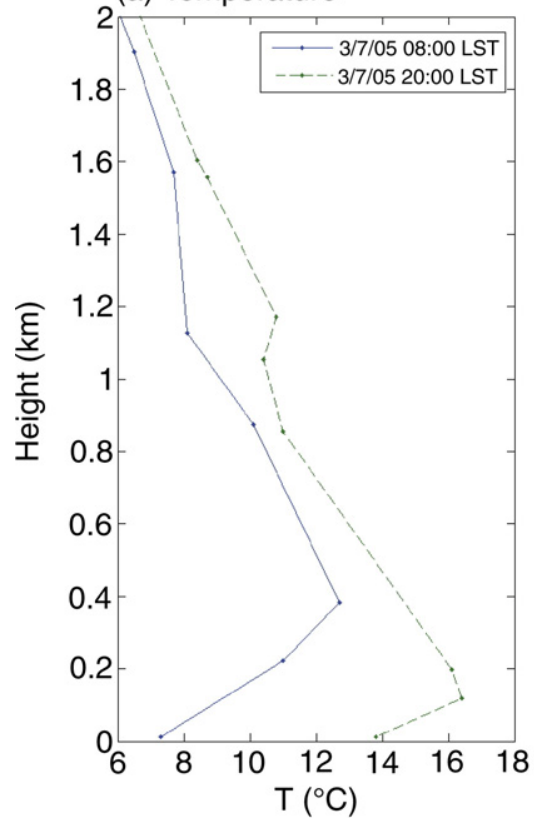

(b) Relative Humidity

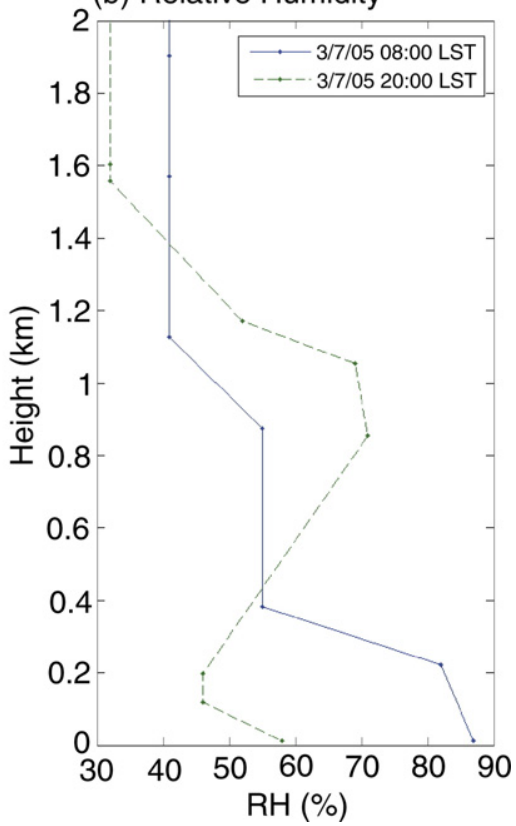

Fig. 5. Radiosonding profiles of (a) temperature and (b) relative humidity in Taipei on March 7, 2005.

descent. Both types were also observed in our study: Fig. 4 displays a typical ILS transition pattern, and Fig. 6 shows the case of descent transition occurred on March
10. They also noticed that the transition sometimes starts in the very early afternoon, similar to the results reported in this paper. (a) Range Corrected Singal

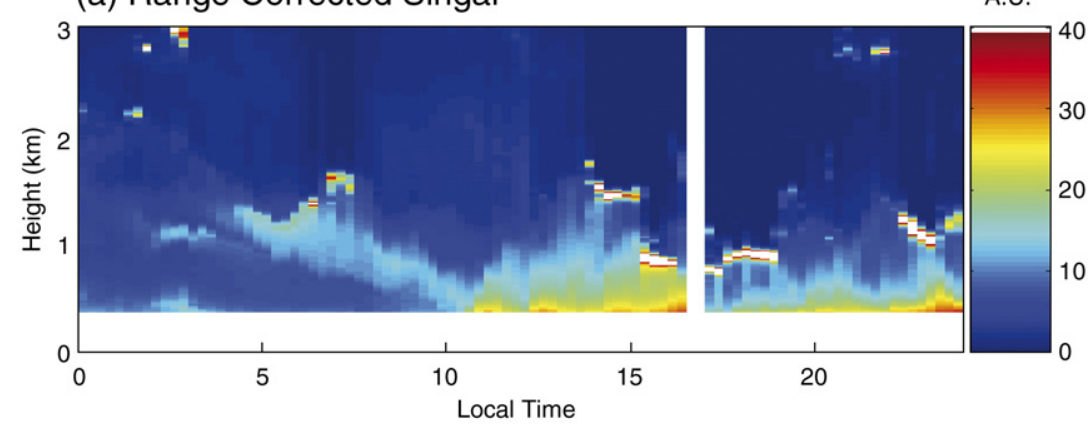

(b) $d\left(\right.$ Pxz. $\left.{ }^{2}\right)$

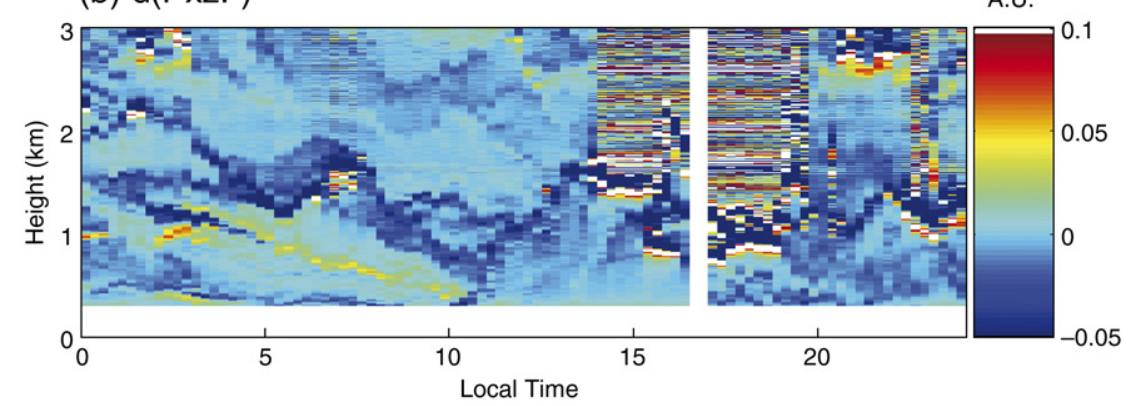

Fig. 6. Time-height plots of (a) range-squared-corrected signal and (b) the first derivative of the LIDAR signal measured on March 10, 2005. The figures present 15-min averages of the LIDAR measurements and have a resolution of $7.5 \mathrm{~m}$ in altitude. 

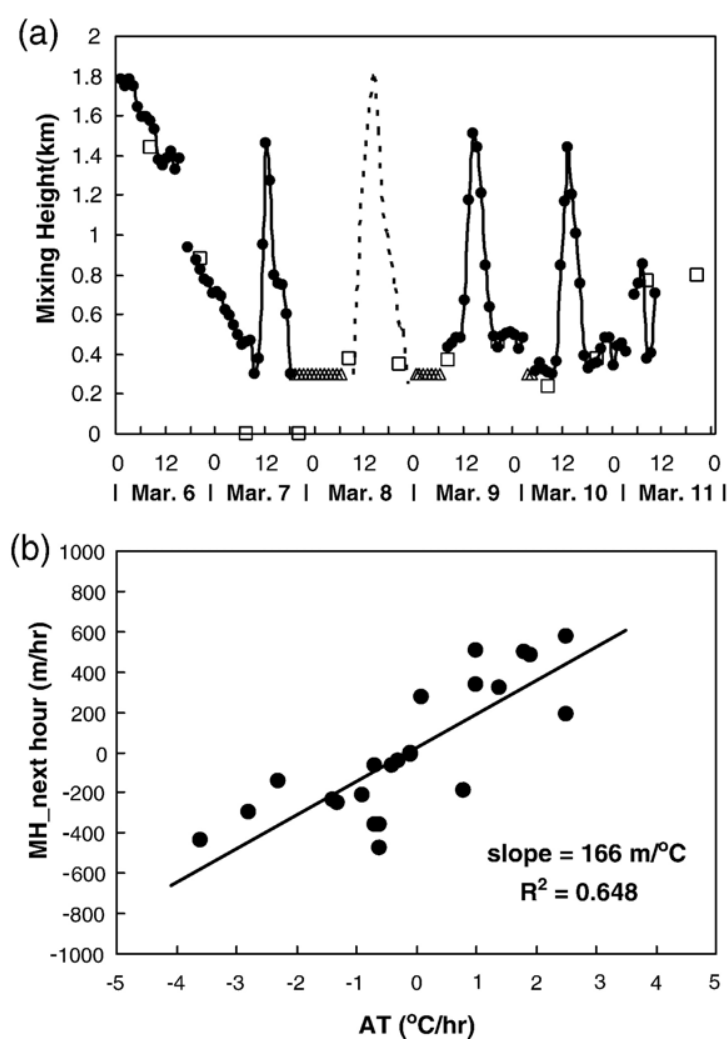

Fig. 7. (a) Hourly mixing height for the episode of this study. The open triangles denote that the mixing height was lower than the detectable range of our LIDAR system $(0.3 \mathrm{~km})$. The open squares denote the mixing height determined by the radiosonding measurements at the BanChiao station. (b) Linear correlation between the changes in ambient temperature and mixing height. The linear regression model was applied to estimate the hourly mixing heights during the daytime of March 8, when the LIDAR system was turned off for maintenance, as shown by the dashed line in the upper panel.

Fig. 7(a) shows the variation of mixing height during the period of this study. Changes in mixing height during daytime (10:00-18:00 LST) are coherent with the changes in ambient temperature, as shown by the good statistical correlation in Fig. 7(b). The hourly increase in mixing height was linearly proportional to the increase in ambient temperature of the previous hour, which means a lag of about $1 \mathrm{~h}$ from the heating up of the air mass to the growth of the mixing layer. Considering the correlations shown in Fig. 7(b) and the meteorological conditions described in the previous section, we can draw the conclusion that the drastic decrease in mixing height was a result of the sharp temperature drop in the afternoon. When the thermal forcing ceased, the convective mixing had to rely on the dynamics of the weather systems. However, as the traveling high-pressure system was just located nearby, Taipei was in the subsidence zone and the convective mixing was suppressed. For instance, on March 7 the drop of air temperature from 12:00 to 18:00 was $-8.1{ }^{\circ} \mathrm{C}$. According to the regression trend shown in Fig. 7(b), the mixing height would have decreased from 1460 to $115 \mathrm{~m}$, which is below the detection range of our LIDAR system.

\subsection{Variations of air quality}

During the period of March 7-10, 2005, Taipei experienced an episode of serious air quality deterioration exactly when the slow-moving high-pressure system was nearby. For the substantial decrease in mixing height in the early afternoon of March 7, air pollutants emitted during the rush-hour period accumulated in the mixing layer. For instance, PM10 and PM2.5 concentrations built up concurrently and reached their respective maxima of 140 and $99 \mu \mathrm{g}^{-3}$ at 20:00 (LST). The pollutants' concentrations decreased slightly during the night and increased again in the morning rush hours of March 8. The hourly concentrations of PM10 and PM2.5 reached 170 and $130 \mu^{-3}$ at 09:00 (LST). Although the LIDAR was turned off for maintenance during the daytime hours of March 8, it is reasonable to expect that a mixing layer should have developed as was the case on March 7 given the similar diurnal patterns of AT and the surface winds shown in Fig. 3. With the measured hourly AT (see Fig. 3) and assuming a mixing height of $0.3 \mathrm{~km}$ for 08:00 (LST), the daytime mixing height on March 8 can be estimated by applying the regression model shown in Fig. 7(b). The estimated maximal mixing height is $1.8 \mathrm{~km}$ occurring at 14:00 (LST). The convective mixing led to the decrease in concentration of the air pollutants around noon: the PM10 and PM2.5 levels declined to 50 and $35 \mu^{-3}$ at 12:00 (LST). Substantial increases of the pollutant concentrations were also observed in the afternoon of March 8. In fact, a drastic rise in the pollutant concentrations occurred in the afternoon of each day during this episode. Fig. 8(a)-(c) shows the diurnal patterns of PM10, PM2.5, and the light scattering coefficient at $550 \mathrm{~nm}$ measured at the Taipei supersite on March 7-10. In addition to the particulate matters, almost all the air pollutants exhibited similar diurnal patterns during this period. For example, Fig. 8(d) and (e) shows the diurnal variations of $\mathrm{CO}$ and $\mathrm{NO}_{x}$ measured at the SJ station during the same period. The patterns of the gaseous species are even more selfconsistent and clearer than those of the aerosols, indicating that the mixing efficiency for gaseous species is better than for aerosols, particularly the coarse particles. 
In addition to the decreased mixing height, the drastic increases of the ground-level concentrations of air pollutants in the afternoon can also be attributed to other factors. One of the possible reasons is a shift in wind direction; however, our results suggest that the influence due to wind direction was relatively minor in the episode of this study. Fig. 3(b) shows that there was indeed a diurnal cycle of wind direction during the episode. However, the shift in wind direction usually occurred at around 19:00-20:00 LST, several hours after the pollutant concentration started to increase (see Fig. 8). Increases in emissions can certainly result in the observed phenomena. In fact, it is difficult to precisely separate the effect of

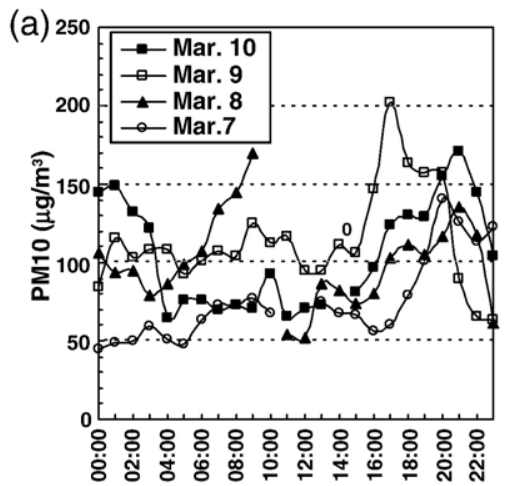

(b)

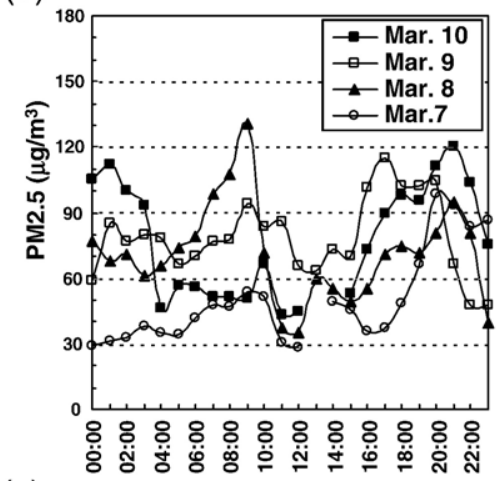

(c)

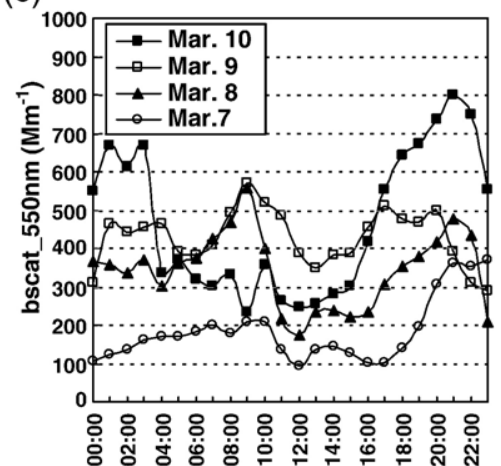

afternoon rush hours from that of a shrinking mixing layer. One reasonable approach is to compare the diurnal pattern of a pollutant for a specific episode with that for average conditions. Fig. 9(a)-(b) illustrates such a comparison of two typical transportation pollutants, $\mathrm{CO}$ and $\mathrm{NO}_{x}$ : the averages for the episode are compared with their respective monthly averages. One can see that the increases in the ambient levels of air pollutants during rush hours are much more pronounced in this episode than under average conditions. The evening peaks of both $\mathrm{CO}$ and $\mathrm{NO}_{x}$ of the episode are higher than their respective monthly averages by a factor of about two, indicating the strong influences due to factors other than rush-hour emissions.

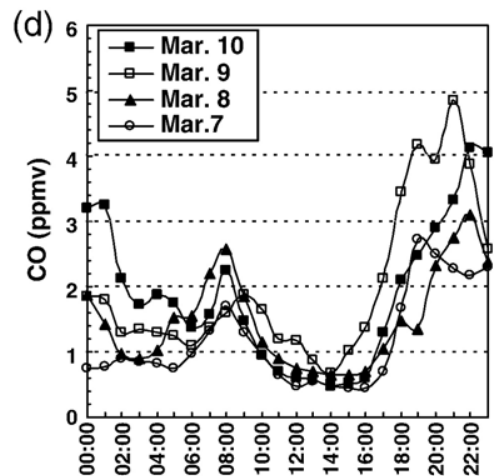

(e)

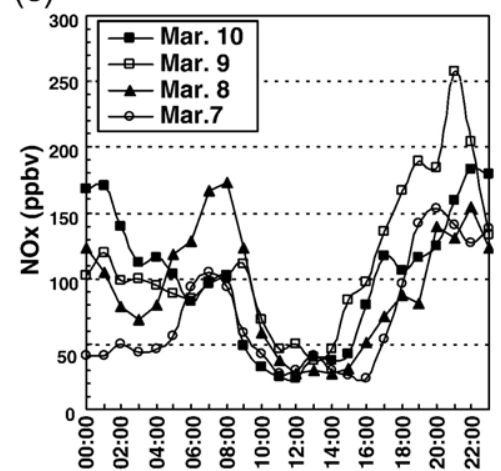

(f)

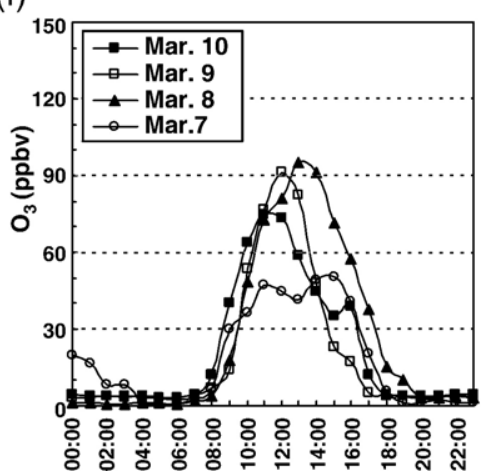

Fig. 8. Diurnal patterns of the concentrations of air pollutants and light scattering coefficient. (a) PM10; (b) PM2.5; (c) scattering coefficient for $550 \mathrm{~nm}$; (d) $\mathrm{CO}$; (e) $\mathrm{NO}_{x}$; (f) $\mathrm{O}_{3}$. 
Table 1 summarizes the linear correlation coefficients between the mixing height and the ambient concentration of each air pollutant for the time periods of 13:0018:00 of March 7 and March 9-10, respectively. On March 7, prior to the episode, the correlation was relatively weak. In contrast, on March 10, almost perfect anti-correlations between the mixing height and the pollutant concentrations were found. The concentrations of air pollutants and the light scattering by aerosols increased proportionally when the mixing height decreased in the afternoon. This shows that the air pollutants were concentrated when the cap of the mixing layer was descending. The poor correlation between $\mathrm{SO}_{2}$ and mixing height is not clear yet. Nevertheless, the results show that the concentration of $\mathrm{SO}_{2}$ in Taipei basin was dominated by factors other than the convective mixing. The concentration of ozone was positively correlated with the mixing height. In Fig. 8(f) the diurnal cycle of ozone mixing ratio indicates that photochemical reactions prevailed during daytime of the episode. Thus, it is reasonable to infer that there was a substantial amount of secondary pollutants formed through photo-
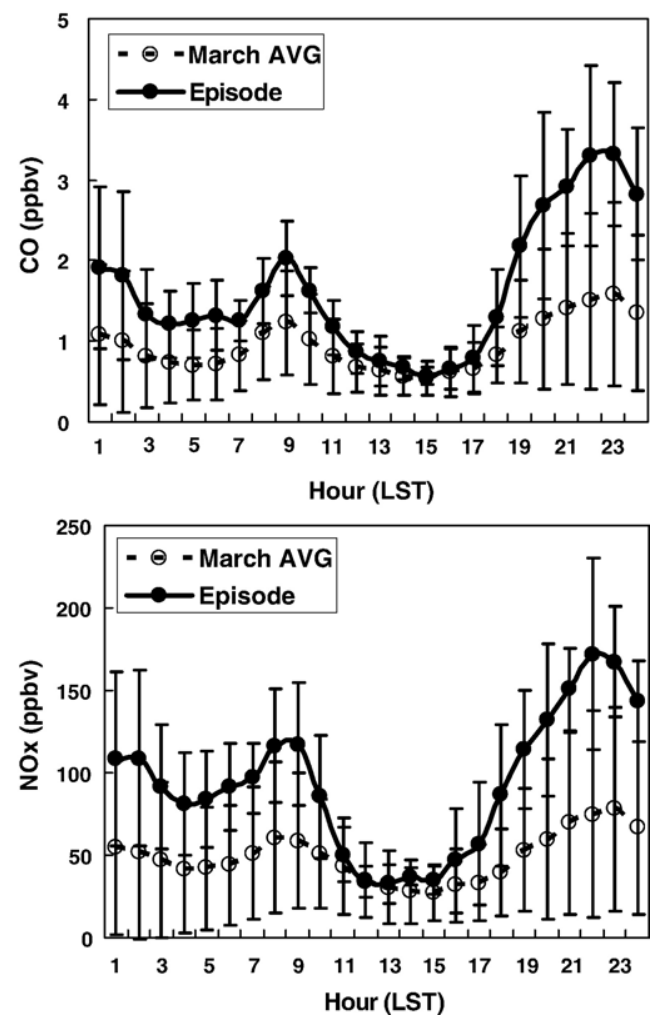

Fig. 9. Comparison between the diurnal variations of typical transportation pollutants $\left(\mathrm{CO}\right.$ and $\mathrm{NO}_{x}$ ) for the episode (March 7-10) and the monthly average of March 2005. The error bars are for the standard deviations of the average values.
Table 1

The correlation coefficients between the mixing height and the ambient concentrations of the respective air pollutants in the afternoon (13:00-18:00) of each day

\begin{tabular}{lrrr}
\hline & March 7 & March 9 & March 10 \\
\hline PM10 & -0.0048 & -0.7460 & -0.9690 \\
PM2.5 & -0.2105 & -0.7240 & -0.9901 \\
$b_{\text {scat-550 nm }}$ & 0.1831 & -0.7368 & -0.9643 \\
$\mathrm{CO}$ & -0.7045 & -0.9268 & -0.8200 \\
$\mathrm{NO}_{x}$ & -0.6280 & -0.8407 & -0.9429 \\
$\mathrm{NMHC}$ & -0.7111 & -0.8724 & -0.9225 \\
$\mathrm{THC}$ & -0.8095 & -0.8286 & -0.9440 \\
$\mathrm{O}_{3}$ & 0.6929 & 0.5052 & 0.9588 \\
$\mathrm{SO}_{2}$ & 0.4139 & -0.8432 & 0.0088 \\
\hline
\end{tabular}

chemical reactions within the mixing layer. The formation of secondary aerosols may explain why the particulate measurements (PM10, PM2.5, and light scattering coefficient) did not significantly decrease as did the gaseous species around noontime due to convective dispersion (Fig. 8). The secondary aerosols were accumulated in the mixing layer, and were concentrated in the afternoon, when the mixing height was decreased. The daily-based anti-correlation between the aerosol measurements and the mixing height warrants that the ambient concentration of aerosols was dominated by the mixing layer dynamics. The extent of photochemical reactions should also be important to the ambient level of aerosols; however, a conclusive remark for the interactions between meteorological and photochemical effects cannot be drawn in this context.

Another noteworthy feature is the built up of nighttime pollutant concentrations as shown in Fig. 8 . It is suggested that the daily build up of pollutants in the night could be a result of the weakening winds (shown in Fig. 3(b)). Evidently wind advection played a critical role in the nighttime air quality, whereas the convective mixing predominated in the daytime. In the case where the synoptic weather conditions tended to inhibit advection, a stagnant atmosphere was formed, resulting in the accumulation of air pollutants during the night.

\section{Conclusions}

The variation of urban mixing layer and its implication for the air quality deterioration episode in Taipei, Taiwan was studied with air quality monitoring data and LIDAR measurements. We found that the urban mixing heights grow proportional to the changes in ambient air temperature with a lag of $1 \mathrm{~h}$. The cap of the mixing layer descended drastically as the thermal forcing declined in the afternoon during this springtime episode. In addition, the shallow mixing layer in the 
afternoon was also attributed partly to the anti-cyclonic subsidence of a nearby high-pressure system. Synoptic conditions inhibited advection and convection of the boundary layer air mass, and therefore reduced the mechanical forcing for the mixing layer.

During the episode examined in this study, the ambient levels of the air pollutants, except ozone, increased consistently with the decreases in mixing height in the afternoon, indicating that the high mixing ratios of the air pollutants in the evening resulted from a reduced dispersion volume. The mixing ratio of ozone, a typical secondary pollutant due to the photochemistry in the troposphere, exhibited a positive correlation with the mixing height. The positive correlation was a result of their common forcing, i.e. solar irradiation. Inferred from this is a substantial production of secondary aerosols, which later on accumulated and resulted in high concentrations of particulate matters in the evening.

The influence of convective mixing on the air quality has been recognized for decades, yet data showing this phenomenon remain rather limited for the lack of temporal resolution in the mixing height measurement. The development and application of LIDAR have made such an investigation possible. Besides, to date, more attention is usually focused on the pollution problems occurring in a morning inversion layer. The results of this study indicated that the air pollution could be even more severe while the mixing layer is getting shallow in the afternoon. Considering the fact that an improvement in the understanding of boundary layer dynamics will most certainly contribute to the development of an air quality forecast model, a well-designed long-term study combining LIDAR and atmospheric chemistry measurements is urgently needed.

\section{Acknowledgements}

This work was supported by the Nation Science Council of Taiwan, R.O.C. through grants NSC-902119-M-002-013, NSC-94-EPA-Z-008-003, NSC-942111-M-001-004, and NSC-95-2111-M-001-004. Partial funding support for the lidar instrument from the College of Science, National Taiwan University, is also greatly appreciated.

\section{References}

Angevine WM, White AB, Senff CJ, Trainer M, Banta RM, Ayoub MA. Urban-rural contrasts in mixing height and cloudiness over Nashville in 1999. J Geophys Res 2003;108:4092.
Ansmann A, Wandinger U, Riebesell M, Weitkamp C, Michaelis W. Independent measurement of extinction and backscatter profiles in cirrus clouds by using a combined Raman elastic-backscatter lidar. Appl Opt 1992;31:7113-31.

Chen W, Kuze H, Uchiyama A, Suzuki Y, Takeuchi N. One-year observation of urban mixed layer characteristics at Tsukuba, Japan using a micro pulse lidar. Atmos Environ 2001;35:4273-80.

Chen WN, Lin PH, Chen TK, Chou CCK, Chen JP. Diurnal cycle of mixing measured by lidar. 23rd International Laser Radar Conference, Nara, Japan, July 24-28; 2006.

Chou CCK, Huang SH, Chen TK, Lin CY, Wang LC. Size-segregated characterization of atmospheric aerosols in Taipei during Asian outflow episodes. Atmos Res 2005;75:89-109.

Cohn SA, Angevine WM. Boundary layer height and entrainment zone thickness measured by lidars and wind profiling radars. J Appl Meterol 2000;39:1233-47.

Dibb JE, Talbot RW, Scheuer EM, Seid G, Avery MA, Singh H. Aerosol chemical composition in Asian continental outflow during the TRACE-P campaign: comparison with PEM-West B. J Geophys Res 2003;108:8815.

Flamant C, Pelon J, Flamant PH, Durand P. Lidar determination of the entrainment zone thickness at the top of the unstable marine atmospheric boundary-layer. Boundary - Layer Meteorol 1997;83: 247-84.

Grimsdell AW, Angevine WM. Observations of the afternoon transition of the convective boundary layer. J Appl Meteorol 2002;41:3

Klett JD. Stable analytical inversion solution for processing lidar returns. Appl Opt 1981;20:211-20.

Kunz GJ, Leeuw G, Becker E, O’Dowd CD. Lidar observations of atmospheric boundary layer structure and sea spray aerosol plumes generation and transport at Mace Head, Ireland (PARFORCE experiment). J Geophys Res 2002;107:8106.

Matthias V, Bosenberg J. Aerosol climatology for the planetary boundary layer derived from regular lidar measurements. Atmos Res 2002;63:221-45.

Menut L, Flamant C, Pelon J, Flamant PH. Urban boundary-layer height determination from lidar measurements over the Paris area. Appl Opt 1999;38:945-54.

Mok TM, Rudowicz CZ. A lidar study of the atmospheric entrainment zone and mixed layer over Hong Kong. Atmos Res 2004;69: 147-63.

Pino D, Vila-Guerau de Arellano J, Comeron A, Rocadenbosch F. The boundary layer growth in an urban area. Sci Total Environ 2004;334-335:207-13.

Seibert P, Beyrich F, Gryning SE, Joffre S, Rasmussen A, Tercier P. Review and intercomparison of operational methods for the determination of the mixing height. Atmos Environ 2000;34: 1001-27.

Strawbridge KB, Snyder BJ. Planetary boundary layer height determination during Pacific 2001 using the advantage of a scanning lidar instrument. Atmos Environ 2004;38:5861-71.

Stull RB. An introduction to boundary layer meteorology. Netherlands: Kluwer Academic Publishers; 1988.

Turner DB. Workbook of atmospheric diffusion estimates. U.S. EPA Report 999-AP-26, Washington, D.C.; 1969. 